\title{
Brigitte Schels
}

Institute for Employment Research (IAB), Germany; University of Erlangen-Nuremberg, Germany

\begin{abstract}
This study investigates social differences in the risk of long-term benefit receipt of young adults in Germany. Although employment is a major route to end social benefit receipt, it may not result in financial independence for all social groups in their early working lives as this also depends on the status of their parents: Do young benefit recipients have unequal chances of making the transition from benefit receipt as soon as they take up employment? How stable is the impact of parents' socioeconomic status on the transition once young adults complete their vocational education? This study conducts an empirical analysis of the careers of a cohort of 18-to-24-year-old Germans who received benefits in 2005 by combining survey data and register data for a six-year observation period. Event history analyses indicate that social differences persist when young adults claim social benefits. In particular, parents' socioeconomic status is positively associated with their offspring's likelihood of ending receipt of social benefits as soon as they are in full-time employment. Parents' socioeconomic status has a relatively stable impact for young beneficiaries irrespective of whether they have completed vocational qualifications or not. The findings suggest that these social differences persist during early working life.
\end{abstract}

\section{Keywords}

Young adulthood, social benefits, event history analysis, intergenerational transmission, transition to working life, parents' socioeconomic status, Germany, cumulative disadvantage

\section{Introduction}

Benefit receipt across generations represents a particularly worrying example of the persistent influence of parents' socioeconomic status on their children's achievements. From the contemporary literature, 
however, relatively little is known of the impact of parents' background on the risk of benefit receipt during young adults' transition to working life. This life stage entails a crucial development in the young person's own social status (Lui et al., 2014). Most young people complete a basic level of education and subsequently enter the labour market. However, a significant proportion of young adults face increasingly complex transitions, including unemployment as well as temporary, part-time or low-paid employment (e.g., Blossfeld et al., 2006; Brzinsky-Fay and Solga, 2016). As a consequence, young adults may remain financially dependent on their parents or rely on state benefits at least temporarily.

This study investigates the structuring effect of parents' socioeconomic background on the risk of long-term benefit receipt over the transition to working life. Recent research on the social stratification of poverty risks over the life course demonstrates that people of different social groups are unequally vulnerable at specific life stages (Vandecasteele, 2011). Regarding the transition to adulthood, the crucial question is whether long-term receipt is particularly related to the family of origin (Kauppinen et al., 2014). This study takes into account that the transition to working life generally includes turning points for ending social benefit receipt, in particular when young people achieve crucial qualifications for the labour market. Depending on their parents' socioeconomic status, do young benefit recipients face unequal chances to end social benefits as soon as they take up employment? Do the differences related to parental background change and lose relevance with an individual's progress in the transition to working life as soon as young beneficiaries have completed vocational training?

Answers are particularly important in terms of a better understanding of how intergenerational disadvantages are reproduced: how do conditions as a youth subsequently relate to the risk of longterm benefit receipt in young adulthood? The paper aims to shed light, theoretically and empirically, on this process of cumulative disadvantage.

The empirical analysis provides an example with regard to young beneficiaries in Germany. Most of the few existing studies on the impact of parents' socioeconomic status on the risk of benefit receipt among young people are from Nordic countries (Lorentzen et al., 2012; Moisio and Kauppinen, 2011; Wiborg and Møberg, 2010). There is still little research on the impact of social origin on young adults' risk of benefit receipt in other European countries; and results are not per se transferable: different types of welfare and transition regimes (Walther, 2006) may moderate the effect of employment transitions and other life course events for different social groups (Vandecasteele, 2009).

The study uses information on a cohort of 18- to 24-year-olds in Germany who began receiving means-tested social benefits at the beginning of 2005. This benefit, also known as unemployment benefit II or, colloquially, Hartz IV, was introduced in Germany in 2005 and combines former unemployment assistance with social assistance. It is a basic income subsidy for 15- to 64-year-olds who are capable of working but who are receiving either no income or inadequate income to support their household and who are not entitled to further insurance benefits (e.g., unemployment insurance) or allowances (e.g., training allowances) (Eichhorst et al., 2008). Under the legal definition established in 2005, young people over the age of 18 are regarded as single person households even if they are living with their parents. Thus, they claim the means-tested benefit independently of their parents' financial resources (Schels, 2013).

\section{Benefit dynamics in perspective: transitions to working life and social origin}

\section{Benefit dynamics and life course events}

There exists a broad international literature (see, e.g., Bane and Ellwood, 1996; Buhr, 1995; Hansen, 2009; Saraceno, 2002) in which the timing and duration of social benefit receipt has been examined from a life course perspective. This literature has emphasised that movements on and off benefit receipt are strongly related to life course events such as marriage, childbirth, separation, job loss or job entry (Leisering and Leibfried, 1999). Recently, this research was extended to the transition to adulthood and 
the process of gaining economic independence (Schels, 2013). Findings show that leaving home, having children, dropping out of school early, and individual's regional mobility on the labour market are predictors of social benefit transitions (Kauppinen et al., 2014). Similiar evidence from recent research on poverty in young adulthood supports this evidence, showing that poverty risks are related to educational attainment and quality of employment (Groh-Samberg and Voges, 2014).

Entry into employment is a major exit route away from benefit receipt (e.g., Bäckman and Bergmark, 2011; Gangl, 1998). The little available empirical evidence on young beneficiaries has shown that young adults are more likely to exit benefit receipt through full-time employment than recipients in their thirties or forties, which can be explained by the in general high labour market mobility of younger people (Gangl, 1998). However, exit opportunities from benefit receipt for young people are still limited, as entry patterns into working life are often unstable, for example, in temporary or low-paid jobs. As a consequence, the start of a job for a young benefit recipient does not necessarily lead to an increase in income above the level of social benefits (Gangl, 1998; Schels, 2011). Once employed, however, the additional income in combination with other inner-family sources of support helps the household in overcoming social benefit receipt (Schels, 2013).

\section{Linking parental background and benefit dynamics}

Literature on the effects of social stratification on life courses is specifically interested in the interaction between social stratification indicators and life course events. Questions include whether the effects of employment transitions, or other life-course events, on poverty and benefit receipt are individualised because the consequences are the same for all social groups or if they vary systematically by social background (Vandecasteele, 2011, 2015; Whelan and Maître, 2008). Recent findings provide evidence supporting the latter perspective: structural inequalities are integrated into the life course and biographical transitions (Vandecasteele, 2009, 2011: 248).

Following this strand of research, the focus here is on social benefit receipt in young adulthood and patterns of intergenerational transmissions. Previous research has shown that (as early as) in young adulthood, social origin has an impact on the risk of social benefit receipt (Beaulieu et al., 2005; Kauppinen et al., 2014; Moisio and Kauppinen, 2011; Wiborg and Møberg, 2010). Furthermore, differences in social origin affect both the risk of unemployment as well as job loss (e.g., Bäckman and Nilsson, 2010), and access to income (Erikson and Jonsson, 1998). The impact of an individual's social origin on their economic vulnerability can still be observed in adult age-groups (Whelan et al., 2013). Further research was particularly interested in the intergenerational transmission of worklessness (e.g., Macmillan, 2014; Schoon, 2014). For example, findings associate poor outcomes of offsprings of workless parents to the cluster of risks that workless families generally face, for example, low parental education and a lack of housing tenure (Schoon, 2014). Only a few studies address the link between life course events and social origin. Findings for Germany have demonstrated that parental socioeconomic background has no direct effect on the employment transitions of benefit recipients (Schels, 2011). Further findings for Nordic countries indicate that parents' social assistance receipt and a young person's early departure from the parents' home are interrelated and increase the risk of social assistance receipt in young adulthood (Kauppinen et al., 2014).

Recent research shows that both individuals' achieved transition to employment and social structures ascribed by the parents' social status affects the risk of benefit receipt. This study focuses on whether the influence of the family of origin moderates the impact of an individual's transition to employment on her or his duration of benefit receipt. In the social stratification literature which suggests a persistence of structural inequalities (Grusky, 2001), the risk of long-term benefit receipt is assumed to be triggered by the social conditions experienced in one's family of origin: these early conditions entail processes that have an impact on the individual's subsequent social standing and opportunities, for example, on the ablity to generate economic resources through employment. Sociological concepts of stratification over the life course address such extensions of inequalities through the "metaphor" of cumulative 
disadvantage and advantage (Mayer, 2009: 424). DiPrete and Eirich (2006) - in their discussion of accumulation - consider two theoretical approaches: the dynamic theory; and the status attainment model. For this study, these approaches help to assess how far the impact of parents' socioeconomic background reaches into the transition to working life, that is, whether it mainly defines the starting position or has a lasting effect on the individual risk of long-term benefit receipt.

\section{Two approaches to cumulative disadvantage}

The most prominent approach to the accumulation of disadvantage and advantage is described in the dynamic theory of the Matthew effect. The metaphor was first used by Merton (1968) to describe how successful academic careers are built but has since been extended to other areas of stratification over the life course. The basic idea is that the outcomes of individuals drift apart over their lifetime because individuals in disadvantegous social positions who have fewer opportunities to make investments than others at early stages in life also accumulate less profit. As a result, even small initial differences cannot be compensated for and grow at each stage of the life course.

Most research on the dynamics of cumulative disadvantage and advantage investigates the growth rate of an outcome variable over time. In a strict sense, the concept considers rising inequality in a population; but it has also been used to describe inequality between social groups (DiPrete and Eirich, 2006: 280). Recent research on the social stratification over the life course asks whether life course transitions accelerate the process of accumulation, making social groups of low status more vulnerable to poverty than groups of higher social status. Hence, unequal risks of poverty are analysed by interacting life course events with social positions (Vandecasteele, 2011: 248, 249). This study follows this approach.

Investigating the group of young social benefit recipients, it is important to bear in mind that young people are unequally exposed to risk factors: ${ }^{1}$ those from low social status backgrounds are more likely to receive social benefits compared to young people from high social status backgrounds (Kauppinen et al., 2014). However, once benefit receipt begins, it is assumed that the disadvantage continues to grow, widening the gap between social groups as they experience unequal chances of leaving benefit receipt. Even in early working life, that is, a life stage in which employment mobility is relatively high, entry into employment does not compensate for relative social differences as benefit recipients from lower social backgrounds achieve less financial security from employment compared to their peers from higher social backgrounds. In conclusion, the first hypothesis is that young beneficiaries have unequal chances of exiting from social benefits as soon as having entered a job: employment provides better chances of leaving social benefits for beneficiaries from families of higher socioeconomic status than it does for beneficiaries from families of lower socioeconomic status (hypothesis 1).

An alternative understanding of the concept of cumulative disadvantage is provided by the status attainment model (DiPrete and Eirich, 2006). It emphasises the development of intergenerational social inequalities. The mechanistic model, as introduced in the classic work on intergenerational occupational mobility between fathers and sons of Blau and Duncan (1967), postulated a systematic path-dependency: a parent's occupation affects offspring's educational attainment and, in turn, occupation. The status attainment model distinguishes between ascribed factors, parents' status, and offspring's achieved factors; more generally, it posits that both influence the offspring's status attainment. Parents' social status mainly affects the starting position of offspring such as educational qualifications. The initial social status of an individual's familial origin is subsequently transferred to an individual's social status over time. With every achievement during the transition from education to the labour market, the influence of parental background on outcomes of their offspring such as income and welfare receipt decreases and becomes less direct (see, e.g., Wiborg and Møberg, 2010).

The status attainment model explores the connection between "origin" status and "destination" status (Schoon, 2008), making it particularly applicable to the analysis of labour market outcomes among adults. However, it cannot completely capture variation in social status among individuals during 
the status attainment process. In the increasingly complex life stage of young adulthood, stages of dependence on one's family and the process of establishing one's own social status may last for different lengths of time and occur over a wide range of ages. In conclusion, the relation between the direct and indirect effects of initial social background on individual outcomes depends on the stage individuals are located at in their transition to adulthood (Lui et al., 2014). In Germany, completing vocational training or tertiary education after compulsory school are crucial stages in the transition to employment and convey further advantages over a person's lifetime (Brzinsky-Fay and Solga, 2016).

Thus, the attainment of vocational qualifications or lack of them is of significant importance to young beneficiaries' labour market outcomes. Furthermore, it is the crucial question whether the influence of parents' social status is related to completed vocational training. To this, the dynamic model and the status attainment model predict different modi of intergenerational transmissions. The latter approach suggests that path-dependencies over the status attainment process lead to a declining impact of parents' status on offspring's outcomes in later stages of the transition to working life. It is assumed that young beneficiaries with no vocational qualifications will find it more difficult to compensate for the initial inequalities by their family status. Differences in the likelihood to exit from social benefit receipt based on their parents' socioeconomic status, as stated in hypothesis 1, should be less pronounced for young beneficiaries who have completed vocational education than for their peers who have not (yet) achieved such a qualification (hypothesis 2a). Young people who have not completed vocational training will be more dependent on their parents' social background than those who have acquired crucial qualifications. In contrast, in the dynamic model, it is assumed that parents' socioeconomic background has a lasting effect on the risk of long-term benefit receipt. Young beneficiaries can exploit their parents' resources at each stage of the transition to working life. Social differentiations are assumed to be observable for young people who have acquired vocational qualifications as well as for those who have not (hypothesis 2b).

\section{Data, sample, and methods}

\section{Data and sample for the analysis}

The data used for this study were administrative data from the German Federal Employment Agency in combination with survey data. The administrative data provide information on social benefit receipt, unemployment and employment subject to social security contributions (which also includes vocational training in firms). As these administrative data do not contain many individual characteristics and contain no information on parents' socioeconomic status, they were combined with data from the Life Circumstances and Social Security survey 2005 (LSS05; Meßmann et al., 2008). The survey uses two representative national cross-sectional samples of 15- to 64-year-old individuals who either received unemployment assistance in December 2004 or unemployment benefit II in January 2005. The samples are drawn from the register of the Federal Employment Agency. Approximately 20,000 individuals were asked about their living conditions, household composition and family, as well as their education and work histories. Only respondents under the age of 25 were asked about their family of origin. The LSS05 study on social benefit recipients aims to provide detailed information on a social group that generally has a low response rate and is therefore underrepresented in most surveys. Accordingly, the response rate to the LSS05 survey was also relatively low, at 38.5 per cent. Nevertheless, these data provide an adequate basis: differences in the distribution of basic characteristics - such as gender or nationality - between respondents in the final sample and persons in the gross sample represent small differences of less than one percentage point (Meßmann et al., 2008: 20).

The following analysis used a subsample of 18- to 24-year olds who received social benefits in January 2005 for the first time. This means that they had not claimed means-tested social assistance or unemployment assistance before January $2005 .^{2}$ In the sample it was possible to consider social differences within a group of young social benefit recipients under homogeneous institutional and 
economic conditions. Among them, 91.2 per cent gave consent to combine their personal interview with the administrative data from the German Federal Employment Agency. The final sample for the analysis consisted of 573 respondents.

The combination of administrative data and survey data provided advantages for the research questions in this paper. ${ }^{3}$ Most other representative data from household panels only capture the subgroup of young beneficiaries in Germany at a minimal level as poor households and social benefit recipients show a generally low participation rate in social surveys. Moreover, the administrative data provided information on the respondents' employment careers and careers in benefit receipt over the complete period of observation and were not restricted by problems of panel attrition, which is particularly important in following people during the unstable life stage of young adulthood. A limitation of the study was that the administrative data only provide information that is important to the labour administration authority. In particular, the data do not capture details of periods of non-employment where people are unavailable to the labour market, such as parental leave, general schooling, vocational training in full-time vocational schools, or university studies.

\section{Analysing transitions from receipt of benefits}

Multivariate event history analysis investigated the duration of social benefit episodes and thus the statistical risk (hazard) of the transition from social benefit receipt, which was the dependent variable in the models. The hazard rate was defined as the conditional probability of terminating benefit receipt in a certain time interval $t$ given lasting benefit receipt up to time $t$ (van den Berg, 2001). As there was no clear assumption of the function of time at risk, a piecewise constant exponential model was used to estimate the hazard rate, introducing dummy variables for each of the first three years after entry into benefit receipt; the hazard rate in the fourth year of benefit receipt and beyond is assumed to be constant. The observation period started in January 2005 and covers six years; observations were right-censored after December 2010. Analyses were performed on all episodes of benefit receipt observed; gaps in the benefit episodes of less than one month were treated as continuous benefit receipt. Fifty-eight per cent of the surveyed young adults were recurrent benefit recipients. ${ }^{4}$ Robust cluster standard errors were used to correct standard errors for repeated observations per person. ${ }^{5}$ The final data included 1,346 benefit episodes for the 573 young adults. The data were transformed to person months covering 22,219 observations.

The major aim of the analysis was to uncover whether the hazard rate of the transition from social benefits is influenced by the young beneficiaries' employment status and their parents' social background when controlling for further covariates which in the literature on benefit dynamics are known to have an influence. The time-variable covariates could change in each month of the period of observation.

Employment status of the young adults was a time-variable variable taken from the available information in the administrative data. The information in the data distinguished between unemployment and three types of employment, making it possible to determine the job quality achieved by the young adults in the labour market: regular full-time employment is the core form of employment while part-time employment and minor employment provide lower levels of financial security and social security. Nonetheless, part-time or minor employment may provide stepping stones to exit from social benefit receipt. Furthermore, there was a residual category of beneficiaries in other forms of non-employment who were not captured completely in the administrative data.

Parents' socioeconomic status was a time-constant variable provided in the survey data: the young beneficiaries were asked for their mother's and father's employment status and occupation when the respondents were 15 years old. The analysis distinguished between young respondents of relatively high socioeconomic status who had at least one parent in qualified employment and three groups of young adults with relatively low socioeconomic status, as they had parents in unskilled or low-qualified employment, in unemployment, or in other non-employment (such as pensioners, the long-term ill, or housewife/houseman). Qualified employment included skilled workers, skilled or executive employees, 
civil servants with skilled and executive tasks, (freelance) professionals, and academics; unskilled or low-qualified employment covered unskilled workers and employees, civil servants in low-grade job positions, freelance employees, farmers, self-employees and family workers. For young people growing up with both parents, the dominance criterion using the information of the parent with the higher socioeconomic status ${ }^{6}$ was applied (Erikson, 1984). This employment-related indicator for parents' socioeconomic background was based on both socioeconomic job status criteria (Erikson and Goldthorpe, 1992), and on information regarding worklessness. The measurement used suggested that crucial familial resources vary between families where the parents had good jobs and families with parental unemployment, underemployment or low-wage/low-status occupations and jobs (e.g., Bradley and Corwyn, 2002; McLoyd, 1997). The categories "parents' unemployment" and "parents in lowqualified or unskilled jobs" made it possible to consider differences among young people of the lower social strata. It was expected that young people who have grown up with unemployed parents have the lowest level of familial resources available. Furthermore, unemployed parents were distinguished from the heterogeneous residual group of non-employed parents who were permanently or long-term out of the (current) active labour force for different reasons. ${ }^{7}$

In addition, young people with and without vocational degrees were considerd in the analysis to examine differences related to achieved labour market resources. As young adults may have achieved a degree during the period of observation, vocational education was a time-variable indicator given in the adminstrative data. Furthermore, the level of general schooling achieved until the start of the period of observation was a further covariate. A low level of general schooling was considered if the young person had completed lower secondary school after nine years of schooling or had no school degree. A medium level was assigned after ten years of secondary school, and a high level with a university entrance diploma after twelve or thirteen years of general schooling. Further indicators of labour market experience, such as the time-variable number of episodes of unemployment and employment were taken from the individual employment biographies in the administrative data. The analysis controlled for recurrent benefit receipt by the number of previous benefit spells.

The analysis also controlled for further household characteristics, individual characteristics, and general economic conditions. Time-variant information on young adult's household composition was taken from the administrative data distinguishing between living alone, living with the parents, living with a partner, living with a partner and children or with children but without a partner. Individual characteristics such as migration status, age, and gender were taken from the LSS05 survey. Seasonal labour market effects were also accounted for (spring, summer, autumn, and winter), as were regional differences between East or West Germany.

Descriptive statistics for the covariates in the model are given in Table 1.

\section{Results}

\section{Main effects of parents' socioeconomic status and individual employment status}

The transition from social benefit receipt and the factors that influence this process were analysed. As a first step, the effects of employment status, parents' socioeconomic status and their relations were assessed, given otherwise equal characteristics. The results are reported in Table 2 as average marginal effects that indicate the difference in transition probabilities between the surveyed group of young beneficiaries and the reference group. For metric independent variables, the average marginal effect indicates to what extent the transition probability changes if the covariate increases by one unit.

Table 2 shows the results of two basic models: model 1a omitted parents' socioeconomic status, model $1 \mathrm{~b}$ considered it. The log likelihood and likelihood ratio test statistics are also presented in Table 2. The test compared the maximised likelihood in model $1 \mathrm{~b}$ including parents' socioeconomic status with the maximised likelihood in model 1a. The significant statistic showed that adding parents' 
Table I. Descriptive statistics.

\begin{tabular}{|c|c|c|c|c|}
\hline Dimension & $\%$ & & $\min$ & $\max$ \\
\hline \multicolumn{5}{|l|}{ Dependent variable } \\
\hline Exits from benefit receipt & 4.4 & & 0 & 1 \\
\hline \multicolumn{5}{|l|}{ Categorial covariates } \\
\hline \multicolumn{5}{|l|}{ Employment status } \\
\hline Unemployed & 35.1 & & 0 & I \\
\hline Employed, full-time & 15.4 & & 0 & 1 \\
\hline Employed, part-time & 5.8 & & 0 & 1 \\
\hline Employed, minor job & 11.3 & & 0 & I \\
\hline Other activity & 32.4 & & 0 & 1 \\
\hline \multicolumn{5}{|c|}{ Parents' socioeconomic status (respondents' age of I5) } \\
\hline Qualified employment & 54.6 & & 0 & I \\
\hline Unskilled and low-qualified employment & 26.9 & & 0 & I \\
\hline Unemployed & 11.8 & & 0 & I \\
\hline Other non-employment & 6.7 & & 0 & 1 \\
\hline \multicolumn{5}{|l|}{ General schooling } \\
\hline Low & 49.3 & & 0 & 1 \\
\hline Medium & 32.4 & & 0 & 1 \\
\hline High & 18.3 & & 0 & I \\
\hline Completed vocational training & 37.4 & & 0 & I \\
\hline \multicolumn{5}{|l|}{ Household composition } \\
\hline Single & 46.6 & & 0 & 1 \\
\hline With partner & 14.2 & & 0 & 1 \\
\hline With partner and children & 17.9 & & 0 & 1 \\
\hline With children, no partner & 9.4 & & 0 & I \\
\hline With parent(s) & 11.9 & & 0 & 1 \\
\hline Male & 46.6 & & & \\
\hline \multicolumn{5}{|l|}{ Migration status } \\
\hline None & 55.0 & & 0 & 1 \\
\hline Ist generation migrant & 30.4 & & 0 & I \\
\hline 2nd generation migrant & 14.6 & & 0 & I \\
\hline Living in East Germany & 47.9 & & 0 & I \\
\hline \multicolumn{5}{|l|}{ Season } \\
\hline Winter & 25.5 & & 0 & I \\
\hline Spring & 26.4 & & 0 & i \\
\hline Summer & 25.1 & & 0 & 1 \\
\hline Autumn & 23.0 & & 0 & 1 \\
\hline Continuous covariates & $\mathrm{m}$ & $s$ & $\min$ & $\max$ \\
\hline Age & 20.0 & $\mathrm{I}, 77$ & 18 & 24 \\
\hline Number of previous social benefit episodes & 0.5 & 0.85 & 0 & 6 \\
\hline Number of previous employment episodes & 2.3 & 2.62 & 0 & 20 \\
\hline Number of previous unemployment episodes & 1.6 & 1.85 & 0 & 12 \\
\hline Person months & 22219 & & & \\
\hline
\end{tabular}

Notes: $\mathrm{m}=$ mean; $\mathrm{s}=$ standard deviation; $\min =$ minimum; $\max =$ maximum; source: LSS 05 , administrative data.

socioeconomic status improved the model fit. In addition to other important factors such as employment status and qualifications, parents' socioeconomic status is an important predictor of the young beneficiaries' likelihood of ending benefit receipt. 
Table 2. Determinants of transitioning from benefits (average marginal effects (AME), significance (sig), standard errors (SE)).

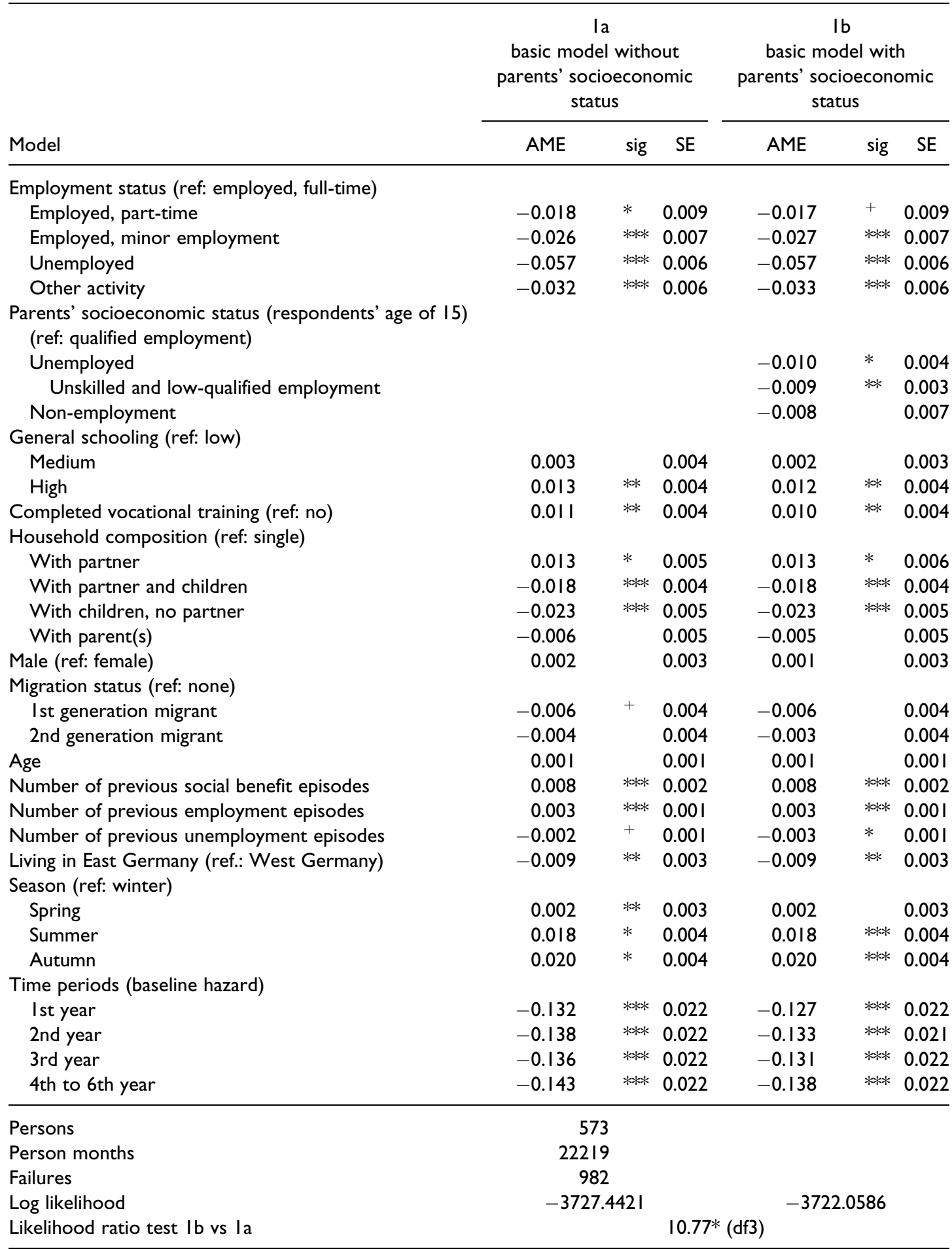

Notes: significance: $* * * p<0.001 ; * * p<0.01 ;{ }^{*} p<0.05 ;{ }^{+} p<=0.1$. 
Results of model $1 \mathrm{~b}$ in Table 2 show the main effects of parents' socioeconomic background and individual employment status on the likelihood and timing of the transition from social benefits. There was a significant singular effect of parental socioeconomic background on the likelihood of young adults ending benefit receipt. Young beneficiaries who grew up with parents who were employed in unskilled or low-qualified employment or were unemployed exited benefit receipt more slowly than young adults with parents engaged in qualified employment. Among the young beneficiaries of January 2005, those of low social origin faced a higher risk of long-term benefit receipt than those of high social origin.

Moreover, when parents' socioeconomic status was added in model $1 \mathrm{~b}$, the impact of beneficiaries' qualifications on the likelihood of ending benefit receipt was only slightly reduced from model $1 \mathrm{a}$ to model $1 \mathrm{~b}$. Thus, the likelihood of transitioning out of social benefit receipt was directly affected by the parents' status and not indirectly via the achieved qualification level of the beneficiaries surveyed. Because parents' resources are important for the educational achievement of their offspring (e.g., Hillmert and Jacob, 2010), this factor may have been emphasised more for the selection into benefit receipt. However, the risk of falling into benefit receipt cannot be observed in the data.

Not surprisingly, the transition from receiving benefits depended on the individual employment status. Compared to being unemployed, the chances of terminating benefit receipt increased as soon as young people contributed to their household's income as they became employed. The chances to make the transition varied with job quality. For example, entering a full-time job was a major predictor of terminating social benefits. Part-time and minor employment were not associated with the same chances of ending benefit receipt as full-time employment.

In line with previous research on intergenerational transmissions of benefit receipt, the results show that both parents' socioeconomic background and the individuals'status in the transition to working life affect the likelihood of terminating benefit receipt. With regard to the strength of the effects, an individual's employment status was a stronger predictor than parental background. The average effects from the estimated sample showed that young beneficiaries whose parents were either unemployed, not employed or in low-qualified employment had each about a one-percentagepoint-lower likelihood of ending their benefit receipt than young people with parents in qualified employment. Thus, the effect of parental socioeconomic background was relatively weak. In the next step, it is examined whether the effects of parental socioeconomic background vary according to the young beneficiaries' employment status. However, first the results for the other influencing factors are summarised.

Qualified young people with vocational degrees and high school qualifications for university entrance showed a higher likelihood of ending social benefit receipt than did those with lower or no qualifications. In addition, previous employment experience as well as unemployment experience were both singular predictors of the transition chances of the surveyed young people. ${ }^{8}$ Young beneficiaries were more likely to stop receiving social benefits sooner the more often they were previously employed. In contrast, the more often they were previously unemployed, the lower the likelihood that young people would transition out of social benefit receipt. Taken together, these results emphasise that long-term benefit receipt is the result of limited individual labour market prospects that developed before social benefits were received. When young people received benefits multiple times, they exited sooner than those receiving benefits for the first time. The results thus indicate a sequential pattern where young people receive benefits for shorter but repeated periods (Schels, 2013).

Furthermore, consistent with previous research on adult benefit dynamics, large households with children were more likely to receive basic income benefits for longer periods than were other households. This finding included both young adults who still were members of their parents' household and young adults who already had children of their own. Young single parents faced the highest risk of remaining on social benefits. As most of them are single mothers, this finding indicates a risk of long-term benefit receipt in particular for females. On the duration of benefit 
receipt, gender itself had no additional impact. The risk of long-term receipt did also not vary between migrants and non-migrants.

\section{Social differences in the effects of individual employment status}

In the next step it is examined whether the impact of the employment status on young adults' chances of exiting from social benefits receipt varied according to their parents' socioeconomic background. Therefore, model $1 \mathrm{~b}$ was extended by including interaction terms between beneficiaries' employment status and parents' socioeconomic status (model 2). Selected results of the estimation are summarised in Table 3. ${ }^{9}$ The estimated average marginal effects indicate the difference in the likelihood of making the transition from social benefits amongst young people with parents in unemployment, low-qualified employment and other non-employment relative to young beneficiaries with parents in qualified employment, who were the reference group right, parents in qualified in employment are the reference group here.

The results show that the parents' socioeconomic background influenced the young beneficiaries' likelihood of terminating social benefits as soon as the young adults were in full-time employment. Compared to young people with parents in qualified employment, the effect of full-time employment on the likelihood of ending benefit receipt was significantly lower for young people who grew up with parental unemployment, parental non-employment or parents in unskilled or low-qualified jobs. The likelihood of ending social benefit receipt was roughly four to five percentage points higher for young people with higher social backgrounds relative to those with lower social backgrounds. This means that full-time employment, in particular, accelerates the transition out of social benefit receipt for young adults whose parents were in qualified employment. However, as can be seen from the overlapping confidence intervals for young people whose parents were in low-qualified employment or unemployed when the respondent was 15 years old, there was no further difference among young beneficiaries of the lower status group.

Moreover, regarding the effects of the other employment statuses considered, there was no clear variation according to parental status. The significantly slower transition rates from social benefits when being employed in part-time, minor employment, unemployment or not being employed were the same for young people of different social backgrounds.

Thus far, the results are widely consistent with the assumption that there are social differences in the possibility of terminating the receipt of social benefits through employment. However, the results only affirm that social differences exist with respect to full-time employment and the chances associated with it to overcome benefit receipt. For all unfavourable employment statuses, however, the analysis does not confirm social differences.

The final step of the analysis explores whether the link between parents' socioeconomic background and employment status is weaker or equally strong in the group of young people with no vocational degree or those with such degrees. Model 3 included a triple interaction term between parents' socioeconomic status, beneficiaries' employment status and beneficiaries' vocational qualification. Again, selected results are presented as average marginal effects in Table 3.

In both groups (young people without vocational qualifications and those with vocational qualifications), parents' socioeconomic background had a structuring effect. When young benefit recipients entered full-time employment, those who grew up with unemployed parents or parents in unskilled or lowqualified jobs, had a significantly lower chance of exiting benefit receipt than did beneficiaries with parents in qualified employment. The difference in the likelihood-to-exit between young people with parents in qualified employment and young people with unemployed parents is almost equal (within about five percentage points) in groups with and without vocational qualifications. However, the estimated difference in the effect of full-time employment between young people with parents in qualified employment and low-qualified employment was somewhat stronger in the group of young people with vocational qualifications. In the small group of young people with non-employed parents, the negative significant difference was only evident in the group of beneficiaries who had completed vocational training. 
Table 3. Social differences and likelihood of transitioning from social benefits, by employment status and vocational qualification level of young beneficiaries (average marginal effects (AME), significance (sig), confidence interval (Cl)).

Parents' socioeconomic status (respondents' age of I5)

\begin{tabular}{|c|c|c|c|c|c|c|c|c|c|c|c|c|}
\hline \multirow{3}{*}{ Model $2^{a}$} & \multicolumn{4}{|c|}{ Unemployed } & \multicolumn{4}{|c|}{$\begin{array}{l}\text { Unskilled and low-qualified } \\
\text { employment }\end{array}$} & \multicolumn{4}{|c|}{ Other non-employment } \\
\hline & \multirow{2}{*}{\multicolumn{2}{|c|}{ AME si }} & \multicolumn{2}{|c|}{$95 \% \mathrm{Cl}$} & \multirow{2}{*}{\multicolumn{2}{|c|}{ AME sig }} & \multicolumn{2}{|c|}{$95 \% \mathrm{Cl}$} & \multirow{2}{*}{\multicolumn{2}{|c|}{ AME sig }} & \multicolumn{2}{|c|}{$95 \% \mathrm{Cl}$} \\
\hline \multirow{2}{*}{\multicolumn{13}{|c|}{ All young beneficiaries }} \\
\hline & & & & & & & & & & & & \\
\hline Employed, full-time & -0.054 & $* * *$ & -0.077 & -0.030 & -0.040 & $* * *$ & -0.060 & -0.020 & -0.046 & & -0.080 & -0.011 \\
\hline Employed, part-time & -0.014 & & -0.052 & 0.023 & -0.022 & & -0.056 & 0.011 & -0.015 & & -0.056 & 0.025 \\
\hline $\begin{array}{l}\text { Employed, minor } \\
\text { employment }\end{array}$ & -0.020 & & -0.042 & 0.001 & 0.003 & & -0.020 & 0.025 & -0.015 & & -0.062 & 0.031 \\
\hline Unemployed & 0.002 & & -0.010 & 0.013 & -0.005 & & -0.013 & 0.003 & 0.003 & & -0.013 & 0.020 \\
\hline Other & 0.001 & & -0.014 & 0.016 & 0.004 & & -0.008 & 0.017 & 0.004 & & -0.014 & 0.023 \\
\hline \multicolumn{13}{|l|}{ Model $3^{b}$} \\
\hline \multicolumn{13}{|c|}{ Young beneficiaries without completed vocational training } \\
\hline Employed, full-time & -0.046 & & -0.079 & -0.013 & -0.026 & & -0.054 & 0.001 & -0.000 & & -0.054 & 0.054 \\
\hline Employed, part-time & 0.001 & & -0.041 & 0.040 & -0.003 & & -0.033 & 0.027 & -0.003 & & -0.078 & 0.072 \\
\hline $\begin{array}{l}\text { Employed, minor } \\
\text { employment }\end{array}$ & -0.026 & & -0.047 & -0.004 & 0.008 & & -0.020 & 0.035 & -0.014 & & -0.066 & 0.037 \\
\hline Unemployed & -0.003 & & -0.018 & 0.012 & -0.003 & & -0.014 & 0.008 & 0.011 & & -0.009 & 0.030 \\
\hline Other & -0.005 & & -0.020 & 0.009 & 0.002 & & -0.011 & 0.015 & -0.002 & & -0.021 & 0.016 \\
\hline \multicolumn{13}{|c|}{ Young beneficiaries with completed vocational training } \\
\hline Employed, full-time & -0.054 & $* *$ & -0.087 & -0.020 & -0.050 & $* *$ & $-0.08 \mathrm{I}$ & -0.020 & -0.075 & *** & -0.116 & -0.033 \\
\hline Employed, part-time & -0.029 & & -0.087 & 0.028 & -0.037 & & -0.095 & 0.021 & -0.031 & & -0.085 & 0.023 \\
\hline $\begin{array}{l}\text { Employed, minor } \\
\text { employment }\end{array}$ & -0.001 & & -0.058 & 0.056 & -0.007 & & -0.044 & 0.030 & & & & \\
\hline Unemployed & 0.009 & & -0.008 & 0.025 & -0.001 & & -0.011 & 0.014 & -0.017 & & -0.034 & -0.000 \\
\hline Other & 0.092 & & -0.016 & 0.200 & 0.006 & & -0.023 & 0.035 & 0.080 & $* *$ & 0.034 & 0.127 \\
\hline
\end{tabular}

Notes: significance: ${ }^{* * *} p<0.001 ; * * p<0.01 ;{ }^{*} p<0.05 ;{ }^{+} p<=0.1$.

The estimated AME indicate the difference in the likelihood of transitioning from social benefits among young people with parents in unemployment, low-qualified employment and other non-employment, each compared to young beneficiaries with parents in qualified employment (reference group).

'Results are based on interaction terms between parents' socioeconomic status and young beneficiaries' employment status.

'Results are based on interaction terms between parents' socioeconomic status, young beneficiaries' employment status and vocational qualification.

Controls: general schooling; household members; gender; migration status; age; number of social benefit episodes; cumulative employment and unemployment experience; living in East Germany; season; and time period.

There are further specific findings for young adults who had not completed vocational training: the results show that beneficiaries with unemployed parents also faced consistently lower exit opportunities from benefit receipt than did their peers with parents in qualified jobs when the beneficiaries were employed in minor jobs. For young adults who had completed vocational training, there was a higher chance of ending benefit support among young people with unemployed or non-employed parents compared to young people with parents in qualified employment in the broad labour category of other employment status. The effects were particularly strong when estimating separate models for women but were also significant in the group of male beneficiaries (not shown in Table 3). These findings may suggest that beneficiaries of low social origin follow non-labour market routes to exit the social benefit program, such as partnerships for young women, and the chances are particularly high in the group with vocational qualifications. However, the administrative data used here did not provide the detailed information necessary for such an analysis. 


\section{Discussion}

In this study, the effect of parents' socioeconomic status on the risk of long-term benefit receipt for a group of 18- to 24-year-old beneficiaries in Germany was examined. The aim was to provide insights into the risks of long-term benefits' receipt and the social structure underlying the young adults' transition to working life. Completing vocational education and entering full-time employment were considered as critical turning points for gaining independence from social benefits.

The study asked whether young benefit recipients still face unequal chances of exiting from social benefit receipt as soon as they take up employment. Overall, the results provide strong evidence of an interaction between parents' socioeconomic background and offspring's employment position. The findings show in line with hypothesis 1 that young people of different social backgrounds have unequal opportunities to leave social benefit receipt as soon as they take up full-time employment. However, other jobs, such as part-time or low-paid employment, generally contribute relatively little to financial independence from benefits across all social groups surveyed.

Furthermore, the question of whether the impact of parental background is less important among young people with completed vocational education relative to young people without vocational education was addressed. The results show that social differentiations regarding the likelihood of terminating the receipt of social benefits were observable in the group of young adults with vocational qualifications as well as for those without such a degree. Differences in the impact of employment status on the likelihood of terminating receipt were relatively stable particularly between young beneficiaries who grew up with unemployed parents and young beneficiaries with parents in qualified employment. Some differences were even more pronounced, for example, among young people with completed vocational training.

In conclusion, the results are in line with a dynamic perspective of cumulative disadvantages that continues to exacerbate inequalities among groups of young beneficiaries during their transition to working life (hypothesis $2 \mathrm{~b}$ ). Young benefit recipients without vocational qualifications, as well as peers who have better labour market resources due to their completed vocational qualifications, are (still) affected by their parents' background. These disadvantages are not compensated by the attainment of an own qualified status in the labour market. The findings do not support hypothesis $2 \mathrm{a}$ of declining effects of parents' socioeconomic background over the course of status attainment.

Using an employment-related measure of parents' socioeconomic status here, the results demonstrate few social differentiations in the transitions from benefits within the lower status group of young beneficiaries. The observed disadvantages are not only tied to parents' unemployment; young benefit recipients whose parents were in unskilled or low-qualified jobs also have relatively few opportunities to exit the social benefit programme through employment. Young people with unemployed parents and parents in unskilled or low-qualified jobs cannot close the gap between themselves and their peers with parents in qualified employment. One explanation may be that the measurement is not clear-cut. Young beneficiaries were asked to look back to the time when they were 15 and parents in unskilled and lowqualified jobs are also likely to have longer episodes of unemployment and vice-versa. The social gradient is observable in comparison to qualified employment; that is, the observed mechanism operates above a certain level of labour market integration. Previous research on the patterns of intergenerational transmission of disadvantage has shown that social origin affects the risk of falling into benefit receipt among young people. The findings here for Germany add that social origin also influences the risk of long-term benefit receipt once young people are on benefits. This research shows that the influence of the family of origin reaches well into the first stages of a young adult's working life. Parents' socioeconomic status has a persistent impact on the accumulation of resources in the course of employment transitions. Thus, it is not enough to consider educational attainment only as the intergenerational transmission of the risk of long-term benefit receipt also needs to be considered.

There remains much to learn regarding the role parents' resources play in re-enforcing the intergenerational transmission of welfare risks. This study cannot verify direct mechanisms at work beyond 
the consideration of social origin. Further analysis of transmission channels such as access to familial economic, cultural and social capital (Bradley and Corwyn, 2002) or aspirations, networks, favouritism, or productivity (Erikson and Jonsson, 1998) requires data that capture more detailed information on the relation between offsprings and their parents. A further restriction in this study was that the administrative data used only cover transitions to employment. Additional important issues for research include the identification of the impact of other life course transitions in young adulthood, such as leaving parental home and family formation on the risk of long-term benefit receipt. As such, partnership decisions and fertility decisions result in social differentiations (Kauppinen et al., 2014). There is thus a need for longitudinal data that address the various spheres involved in the transition to adulthood.

Thus far, the presented analysis of beneficiaries in Germany as well as previous research for Nordic countries indicate patterns of intergenerational transmission of inequalities in social benefit receipt. However, it remains an open question whether patterns of intergenerational transmission are specific for certain European welfare states and welfare transition regimes. Comparative analyses and the construction of internationally comparable data sets would be ideal. Until now, for example, panel data in Europe rarely manage to follow young people through life passages. Young poor individuals and young beneficiaries are particularly underrepresented in existing panel data. Often surveys among benefit recipients also have a relatively low response rate - issues that also present a limitation in this study.

Despite these caveats, this analysis tracks the intergenerational transmission of inequalities within a group of young adults who, at least once in young adulthood, have required financial support from the state. The findings resonate with the recent strand of literature on the social stratification of the life course. In terms of cumulative disadvantage, young beneficiaries of lower social origin still accumulate fewer resources during the transition to employment than beneficiaries of higher social origin. Consequently, the risks and the experience of long-term benefit receipt are distributed unequally.

\section{Funding}

The author(s) received no financial support for the research, authorship, and/or publication of this article.

\section{Notes}

1. In the following, the phrase cumulative disadvantage is used because young benefit recipients are, at least temporarily, in a relatively disadvantageous social position.

2. This selection limits the heterogenity in the group of benefit recipients based on their benefit receipt histories. While detailed information on previous receipt of unemployment assistance is available in the adminstrative data, the data do not include any information on previous social assistance receipt. The selection of the sample uses information in the survey if the young people have been in receipt of social assistance ever before.

3. Administrative data do not capture information on all young people in Germany, the data do not allow measurement of the selective process of falling into benefit receipt.

4. Kaplan-Meier estimations show for the sample that $50 \%$ of all singular benefit episodes lasted up to one year. Cumulating the duration of all episodes per person, half of the young social benefit recipients were on benefit receipt for 36 months or longer.

5. The results have been confirmed by robustness tests using discrete time random effect models.

6. There is empirical evidence for Germany that the parent with the higher status is more influential than the other parent for their children's outcomes (Korupp et al., 2002). In the sample of young beneficiaries, $45 \%$ of the beneficiaries had a father holding the highest status position, $31 \%$ had parents with equal socioeconomic status, and $10 \%$ had a mother holding the highest position. Further, $14 \%$ lived with only one parent when they were 15 years old. Testing the effect of the information on this 
composition in an additional model specification yielded no significant impact on the likelihood of leaving benefit receipt; the effect of the parents' socioeconomic status remained robust. Thus, there is no evidence that the holding of the dominant position by either the father or the mother makes a difference within the group of young beneficiaries.

7. The social differentiations observable between young beneficiaries with unemployed parents and parents in qualified employment are covered when collapsing parental unemployment and nonemployment into one single category.

8. Models including employment and unemployment experience separately indicate that employment experience had a robust effect independent of previous unemployment experience, but the effects of unemployment experience were covered when not controlling for employment experience. Furthermore, the effect of the number of previous social benefit episodes remained robust in each model specification. This also indicates that careers in social benefit receipt is a singular direct influencing factor.

9. The full models are available from the author upon request.

\section{References}

Bäckman O and Bergmark A (2011) Escaping welfare? Social assistance dynamics in Sweden. Journal of European Social Policy 21(5): 486-500.

Bäckman O and Nilsson A (2010) Pathways to social exclusion - a life-course study. European Sociological Review 27(1): 107-123.

Bane MJ and Ellwood D (1996) Welfare Realities: From Rhetoric to Reform. Cambridge, MA: Havard University Press.

Beaulieu N, Duclos JY, Fortin B, et al. (2005) Intergenerational reliance on social assistance: Evidence from Canada. Journal of Population Economics 18(3): 539-562.

Blau PM and Duncan OD (1967) The American Occupational Structure. New York, NY: Wiley.

Blossfeld HP, Klijzing E, Mills M, et al. (eds) (2006) Globalization, Uncertainty and Youth in Society: The Losers in a Globalizing World. London, UK: Routledge.

Bradley RH and Corwyn RF (2002) Socioeconomic status and child development. Annual Review of Psychology 53(1): 371-399.

Brzinsky-Fay C and Solga H (2016) Compressed, postponed, or disadvantaged? School-to-work-transition patterns and early occupational attainment in West Germany. Research in Social Stratification and Mobility. Online first: doi:10.1016/j.rssm.2016.01.004.

Buhr P (1995) Dynamik von Armut. Dauer und Biographische Bedeutung von Sozialhilfebezug. Opladen, Germany: Westdeuscher Verlag.

DiPrete TA and Eirich GM (2006) Cumulative advantage as a mechanism for inequality: A review of theoretical and empirical developments. Annual Review of Sociology 32(2006): 271-297.

Eichhorst W, Grienberger-Zingerle M and Konle-Seidl R (2008) Activation policies in Germany: from status protection to basic income support. In: Eichhorst W, Kaufmann O and Konle-Seidl R (eds) Bringing the Jobless into Work? Experiences with Activation Schemes in Europe and the US. Berlin, Germany: Springer, pp.17-68.

Erikson R (1984) Social class of men, women and families. Sociology 18(4): 500-514.

Erikson R and Goldthorpe JH (1992) The Constant Flux: A Study of Class Mobility in Industrial Societies. Oxford, UK: Oxford University Press.

Erikson R and Jonsson JO (1998) Social origin as an interest-bearing asset: Family background and labour-market rewards among employees in Sweden. Acta Sociologica 41(1): 19-36 
Gangl M (1998) Sozialhilfebezug und Arbeitsmarktverhalten: Eine Längsschnittanalyse der Ubergänge aus der Sozialhilfe in den Arbeitsmarkt. Zeitschrift für Soziologie 27(3): 212-232.

Groh-Samberg O and Voges W (2014) Precursors and consequences of youth poverty in Germany. Longitudinal and Life Course Studies 5(2): 151-172.

Grusky DB (2001) Social Stratification: Class, Race, and Gender in Sociological Perspective. Boulder, CO: Westview Press.

Hansen HT (2009) The dynamics of social assistance recipiency: Empirical evidence from Norway. European Sociological Review 25(2): 215-231.

Hillmert S and Jacob M (2010) Selections and social selectivity on the academic track: A life-course analysis of educational attainment in Germany. Research in Social Stratification and Mobility 28(1): 59-76.

Kauppinen TM, Angelin A, Lorentzen T, et al. (2014) Social background and life-course risks as determinants of social assistance receipt among young adults in Sweden, Norway and Finland. Journal of European Social Policy 24(3): 273-288.

Korupp SE, Ganzeboom HB and Van Der Lippe T (2002) Do mothers matter? A comparison of models of the influence of mothers' and fathers' educational and occupational status on children's educational attainment. Quality and Quantity 36(1): 17-42.

Leisering L and Leibfried S (1999) Time and Poverty in Western Welfare States: United Germany in Perspective. Cambridge, UK: Cambridge University Press.

Lorentzen T, Dahl E and Harsløf I (2012) Welfare risks in early adulthood: A longitudinal analysis of social assistance transitions in Norway. International Journal of Social Welfare 21(4): 408-421.

Lui CK, Chung PJ, Wallace SP, et al. (2014) Social status attainment during the transition to adulthood. Journal of Youth and Adolescence 43(7): 1134-1150.

Macmillan L (2014) Intergenerational worklessness in the UK and the role of local labour markets. Oxford Economic Papers 66(3): 871-889.

Mayer KU (2009) New directions in life course research. Annual Review of Sociology 35(1): 413-433.

McLoyd VC (1997) The impact of poverty and low socioeconomic status on the socioemotionalfunctioning of African-American children and adolescents: Mediating effects. In: Taylor RD and Wang M (eds) Social and Emotional Adjustment and Family Relations in Ethnic Minority Families. Mahwah, NJ: Erlbaum, pp.7-34.

Merton RK (1968) The Matthew effect in science. Science 159(3810): 56-63.

Meßmann S, Bender S, Rudolph H, Hirseland A, et al. (2008) Lebenssituation und Soziale Sicherung 2005 (LSS 2005). IAB-Querschnittsbefragung SGB II. FDZ-Datenreport 04/2008. Nuremberg, Germany: IAB. Available at: http://doku.iab.de/fdz/reporte/2008/DR_04-08.pdf (accessed 27 November 2016).

Moisio P and Kauppinen TM (2011) The intergenerational correlation of social assistance and selection bias in the Finnish population data. Research on Finnish Society 4(2011): 7-15.

Saraceno C (ed) (2002) Social Assistance Dynamics in Europe: National and Local Poverty Regimes. Bristol, UK: The Policy Press.

Schels B (2011) Young beneficiaries' routes off benefits through labour market integration. the case of Germany. Zeitschrift für ArbeitsmarktForschung 44(3): 261-278.

Schels B (2013) Persistence or transition: Young adults and social benefits in Germany. Journal of Youth Studies 16(7): 881-900.

Schoon I (2008) A transgenerational model of status attainment: The potential mediating role of school motivation and education. National Institute Economic Review 205(1): 72-82. 
Schoon I (2014) Parental worklessness and the experience of NEET among their offspring: Evidence from the Longitudinal Study of Young People in England (LSYPE). Longitudinal and Life Course Sudies 5(2): 129-150.

Vandecasteele L (2009) Poverty trajectories after risky life course events in different European welfare regimes. European Societies 12(2): 257-278.

Vandecasteele L (2011) Life course risk or cumulative disadvantage? The structuring effect of social stratification determinants and life course events on poverty transitions in Europe. European Sociological Review 27(2): 246-263.

Vandecasteele L (2015) Social class, life events and poverty risks in comparative European perspective. International Review of Social Research 5(1): 61-74.

Van den Berg GJ (2001) Duration models: Specification, identification and multiple durations. In: Heckmann JJ and Leamer E (eds) Handbook of Econometrics, Volume 5. Amsterdam, The Netherlands: Elsevier, pp.3381-3460.

Walther A (2006) Regimes of youth transitions: Choice, flexibility and security in young people's experiences across different European contexts. Young 14(2): 119-139.

Whelan CT and Maître B (2008) "New" and "old" social risks: Life cycle and social class perspectives on social exclusion in Ireland. The Economic and Social Review 39(2): 131-156.

Whelan CT, Nolan B and Maître B (2013) Analysing intergenerational influences on income poverty and economic vulnerability with EU-SILC. European Societies 15(1): 82-105.

Wiborg ØN and Møberg RJ (2010) Social origin and the risks of disadvantage in Denmark and Norway: The early life course of young adults. Work, Employment and Society 24(1): 105-125.

\section{Author biograhy}

Brigitte Schels obtained a $\mathrm{PhD}$ from the University of Mannheim in 2012. She was recently appointed as an assistant professor (German Juniorprofessur) in labour market sociology at the University of ErlangenNuremberg. She also holds a research position at the German Institute for Employment Research (IAB). Her current research focuses on the school-to-work transition, occupational aspirations, and youth poverty. 